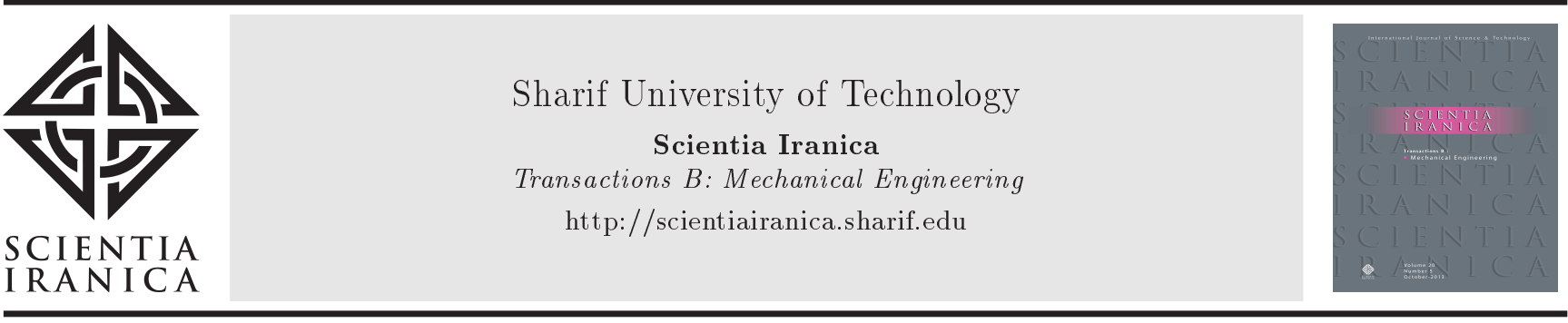

\title{
Experimental assessment of the redistribution of 3D residual stresses during early fatigue at split-sleeve cold expanded reamed $\mathrm{A} / \mathrm{C}$ fastener holes
}

\author{
A. Tamer Özdemir* \\ Department of Materials \& Metallurgy Engineering, Faculty of Technology, Gazi University, Ankara, Turkey. \\ Received 11 June 2014; received in revised form 12 March 2017; accepted 14 August 2017
}

\section{KEYWORDS \\ Fastener holes; Cold expansion; Residual stress; Fatigue.}

\begin{abstract}
Cold expansion is an effective technique of inducing favorable compressive residual stresses around fastener holes which are essentially vital for improving fatigue performances of aircrafts. The benefit is derived through the magnitude and distribution of the compressive stress field. Stress gradients are entirely contingent on the type of the cold expansion, local geometry of the hole, and characteristics of the metallic structure. During cyclic loading, however, initial residual stresses do not remain stable. In the present work, specimens with $4 \%$ split-sleeve cold expanded and reamed holes were cycled at the fatigue limit for short periods. A recent method of Combined Step Drilling-Fourier Series Solution 'ATÖzdemir Method' was employed to appraise the continual redistributions of residual hoop stresses on the side of the hole subjected to cyclic load. Some results were compared with those of diffraction methods and Artificial Neural Network (ANN) modeling, where close similarities in stress distributions were confirmed. It is clear that the material nearby the hole is dynamically hardening during early fatigue; in response, compressive residual stresses along the bore are gradually increasing until the onset of cracking. Short fatigue cracks are mostly initiated from the mandrel entrance side, where, subsequently, residual hoop stresses begin to relax considerably.
\end{abstract}

(C) 2018 Sharif University of Technology. All rights reserved.

\section{Introduction}

Fastener holes are indispensable during construction of civil and military aerospace vehicles. However, being common stress concentrators, they are at risk and inherently vulnerable to fatigue damaging [1,2]. The danger becomes gravely serious as the demand for minimum structural weight to improve aircraft performance increases. Due to the simplicity of assembling and dismantling processes, mechanical joints are routinely applied where the load transfer from one component

\footnotetext{
*.E-mail address:2007atam@gmail.com
}

to another is primarily provided through the bolts in shear or by friction at the contacting surfaces by means of fastener clamping.

To guarantee the long-term fatigue life and structural safety, cold expansion of fastener holes has been applied virtually to the assembly of aircraft structures for more than four decades. Numerous methods available all simply require the insertion of an oversized hard tool into plastically enlarged bore of the hole [3]. After disengagement of the tool, the elastic contraction of the surrounding material forces the yielded zone into compression, resulting in a selfequilibrating compressive residual stress field around the hole. Opposite to the applied tensile and cyclic loads, this stress field is very effective in reducing the 
stress concentration at the hole. Thus, fatigue life increases two to ten folds [3-7], usually due to retarding crack propagation rather than initiation [6-8].

The most common and effectively used technique in the aircraft industry is the split-sleeve process invented by the Boeing Airplane Company in the early 1970s and later improved and marketed by Fatigue Technology Incorporated (FTI) of Seattle, USA [3]. This method is extensively in practice to improve the fatigue life of fastener holes, which is an important area of fatigue cracking in giant-weighted commercial aircrafts. The process involves pulling an over-sized tapered mandrel through an internally lubricated expandable split-sleeve. The sleeve provides the advantage of avoiding direct contact of the sliding mandrel with the bore, and so the lateral flow of the material is minimized. Practically, the degree of cold expansion in the industry varies between 2 to $6 \%$ because residual stress distributions change depending on numerous conditions such as material properties, the shape and the dimensions of the component, the position and size of the hole, and even the position of the split inside the hole $[3,5,9,10]$.

Mathematical, computational, and experimental techniques are used widely to determine the residual stresses at cold expansion. Mathematical derivations mostly employ closed-form solutions adopting already existing solutions of thin walled [11-15] and thick walled [16-20] tubes subjected to an internal pressure. Further, strain-hardening behavior [13,14,1618], elastic unloading [11], and nonlinear elastic-plastic behavior in both loading and unloading $[15,20]$ of the material after cold expansion were considered. Serious deficiencies of the mathematical models mostly arise from the limitations of small deformation theory for strains (5\%). Cold expansion strains, however, are generally beyond this limitation ( $8 \%$ ).

A numerical way of predicting residual stresses is the Finite-Element Method (FEM) that can cover material, geometrical, and boundary non-linearity properties. FEM mostly considers reverse yielding and unloading [21], reverse yielding zone on elastic plastic unloading [22], and the contribution of the stress state as plane stress or plane strain conditions [23].

Residual stresses can also be determined experimentally [4,8-10,22,24-48]. Experimental analyses can be classified as non-destructive and destructive methods. Non-destructive techniques are X-rays and neutrons; the two types of radiation are generally used for scattering studies in bulk materials. For stress measurements, they involve measuring smalldimensional changes in the lattice as micro-strains using the theory of the Bragg's law [24-29,31,36-47]. $\mathrm{X}$-ray sources are simple, easy to install, so cheap, and widely spread, yet they can practically only measure stresses at very thin sections or near-to-surface regions
$(100 \mu \mathrm{m})$. Unfavorably, neutron sources are nuclear reactors which are so rare and expensive; however, neutrons can penetrate easily into the bulk (30-40 $\mathrm{mm})$. Both diffraction techniques, however, are not favored to be used near to a hole or a groove. Only a part of the collimated detector can trace the whole gauge volume, resulting in false strains, thus making analysis of the residual stress impractical $[31,47]$.

High-energy synchrotron strain measurement technique has been newly developed. It enjoys very high resolution (1-200 nm), fast data acquisition, complete two-dimensional strain mapping, and highresolution tomography imaging. Unfortunately, this technique is not ubiquitous and virtually is not operational; however, due to high photon flux and small beam divergence, the method will be more profitable in the future $[49,50]$. Lately, some preliminary measurements of residual strains at several segments along the bore of cold expanded holes with and without cracks have been attained [51].

Destructive methods are principally employed to assess changes in macro-strains after a small piece of material is discarded from a component [24]. Depending on the shape, there are several efficient techniques presented. An elegant destructive method of measuring residual stresses in tubes and rods is the Sachs method [52-54]. This method entails cutting thin layers from the bore of a hollow cylinder to measure the resulting changes in strains from the perimeter. The technique has been lately improved to quantify residual stresses in disc-like bodies [24,28-30,32-34,40]. However, Sachs method can simply describe the average of the residual stress distribution in two dimensions.

Extensive literature covers so many results of analytical, numerical, and experimental methods [1,2,7,1116,19,25-34,36-48,55-59], which do not entirely match each other. As a rule of thumb, results indicate that residual hoop stresses close to cold expanded holes are highly compressive and can be recommended for additional safety of the structure to last longer. However, predictions of crack growth from cold expanded holes are usually not conventional; however, in several cases, the initial growth is typically underestimated and, then, overestimated $[27,39,41-44,59,60]$.

Firstly, the inconsistency is attributed to the use of two-dimensional models which is still ignored through thickness residual stress variation around a cold expanded hole $[27,56,58-60]$. Thus, the twodimensional cold expansion modeling relies on a uniform radial expansion and, thus, assumes an averaged stress distribution along the bore. To incorporate cold expansion in performance into advanced safety calculations, it is necessary to build up a more realistic knowledge base about the upshot of the cold expansion process. To suggest a precise solution for fatigue life of aircraft components containing cold 
expanded holes, above all, an accurate description of the complete three-dimensional stress field encompassing the hole is required. Only recently, several destructive and non-destructive experimental studies [28-31,35-48] have been carried out to measure the three-dimensional nature of residual stresses to show the non-uniform characteristic of through-thickness residual stress variation [28-30,35,37-39,45-48] and nonaxisymmetric behavior of residual stresses about the hole [28-30,32-34,36-41,45-48]. Some recent numerical analyses $[35,46,48,57-59]$ have also proved the nonuniformity and complexity of the residual stress distributions.

It is now clear that mandrel cold expansion methods (ball and solid mandrels, split-sleeve, and split mandrel) generate complex and highly non-uniform three-dimensional residual stress fields. This is due to the presence of different material constraints throughout the plate thickness during cold expansion of the hole, where the lack of out-of-plane constraints of the material during cold expansion process leads to significant surface upsets, and, as a result, the least compressive residual stresses are on the mandrel inlet side with a potent of premature cracking $[11,17,27,60-$ $62]$. However, recently, a new method and tooling has ensured pure radial cold expansion, introducing almost uniform residual hoop stress distributions about the hole along its axis having a minimized and symmetric gradient with respect to the plate mid-section. This is an advantage against conventional mandrel cold expansion methods, where the method is now called a 'symmetric cold expansion technique'. In fact, the fatigue improvement has been proven by fatigue cyclic tests [63-65]. On the other hand, to obtain residual stress, pre-stress, and strain distributions created by cold expansion and bolt clamping forces and also the stress and strain distributions under cyclic loadings, three-dimensional finite-element models have been employed to predict the fatigue crack initiation life. Results show that there is good agreement between numerical and experimental results of fatigue, where life percentages of bolt-treated samples increase considerably, compared to those of the plain hole specimens [66,67].

Secondly, the redistribution of residual stress, particularly residual hoop stress relaxation, is not considered effective in predictions $[42,43]$. The evidence of residual stress redistribution comes from an early work on fatigue induced residual hoop stress decay at split-sleeve cold expanded holes occurring even within the fatigue limit [8]. The data available were twodimensional and rough.

In fact, some preliminary investigations and formulations depending on experimental residual stress measurements were accomplished many years ago [6872]. These predictions were mostly confined to the hole vicinity. Stress decay depends on many factors such as dimensions and material properties of the body, degree of cold expansion, and external cyclic loading. Fatigue loading may activate stress relaxation, even when the average of the mechanical loads does not exceed the elastic-plastic limit. About half of the residual stress relieves during the early stages of fatigue. Precise measurement of the degree of relaxation is not an easy task. Recent numerical studies have underlined the importance of the use of real stress redistributions in predictions. It is obvious that residual stress varies during crack growth [73,74]. The numerical solutions using different kinematic hardening rules for open holes [74] have been reported to be in agreement with the available experimental results of the previous work [8].

Consequently, analysis of crack growth and redistribution of residual stress in three dimensions, especially in the presence of a complicated residual stress field is still unclear and requires justification. With the present knowledge, aircraft designers and manufacturers in design optimization cannot use overpredicted fatigue life of cold expanded joints. It is necessary to develop a more complete information base on the effect of cold expansion on fatigue life of the component. In practice, however, the majority of holes used in aircraft assembly are finish-reamed ones to be sized after expansion to fit the tolerance.

The objective of this work is to improve the present knowledge based on redistributions of residual stresses at cold expanded and finish-reamed holes during early fatigue stage. In conjunction with fatigue tests, principles of Sachs hole drilling method will be used to collect available data from dynamically load-applied side of the hole. Accordingly, the novel method of Combined Step Drilling-Fourier Series Solution 'ATÖzdemir Method' [60,61] will be practiced quantitatively to represent the changes in residual hoop stress fields close to the bore. From the same test samples, crack initiations will also be monitored to verify the consequential effect of cracking on residual stress rearrangements.

\section{Experimental procedures and methods}

\subsection{Method of cold expansion and fatigue tests}

The material is a $7050-\mathrm{T} 76$ aluminum alloy plate $\left(5 \times 40 \times 300 \mathrm{~mm}^{3}\right.$ in dimensions $)$ with a central hole of $8.69 \mathrm{~mm}$ in diameter. The hole was later cold expanded $4 \%$ by a conventional FTI split-sleeve method (Figure 1). During the process, a $0.2 \mathrm{~mm}$ thick self-dry molybdenum disulfide lubricated sleeve was attached to a mandrel. Thus, the total diameter of 9.04 $\mathrm{mm}$ tool assembly was inserted into the hole. The split of the expansion sleeve was always aligned along the 


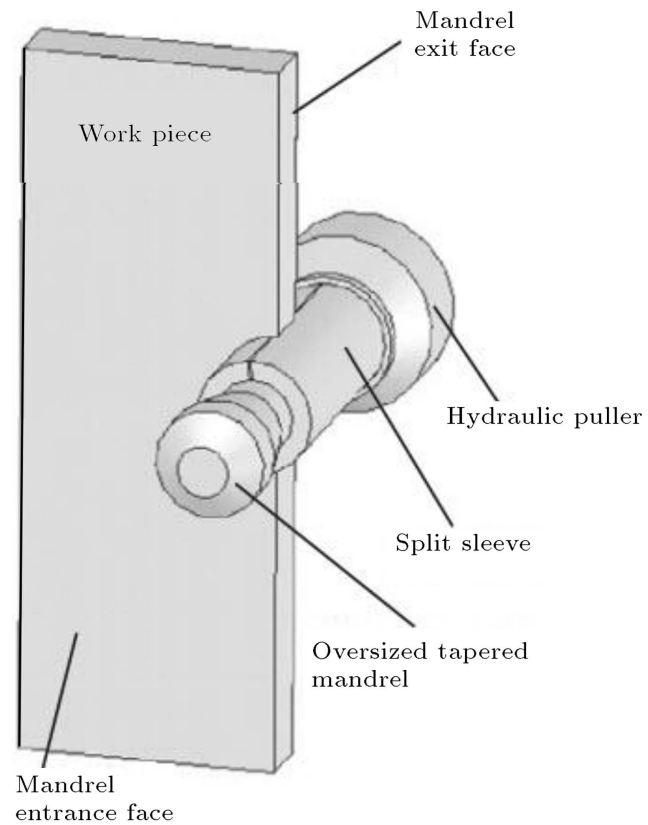

Figure 1. Cross-section of work-piece and FTI cold expansion process assembly.

length of the plate, which was parallel to the fatigueloading axis. As the tool penetrated in, the hole's edge expanded non-uniformly as the sleeve opened, and at the end of the process, the size of the hole was about $8.95 \mathrm{~mm}$. The surface of the hole, where the split was positioned, always formed a ridge sometimes called as the 'pip' (Figure 1). The position of the pip was chosen as $0^{\circ}$, and other locations perpendicular and opposite to the pip were labeled as $90^{\circ}$ and $180^{\circ}$, respectively. For simplicity, the side of the hole, into which the mandrel entered, was considered as 'inlet', and the other mandrel leaving side was considered 'outlet'. The majority of cold expanded holes used in the industry were reamed to a tolerable size to fit a fastener after expansion. Therefore, holes were reamed to a final size of $9.52 \mathrm{~mm}$ and de-burred with slot-drilling without any additive, such as coolants. All specimens were then prepared for fatigue tests.

It is of course well known that the FTI split-sleeve method generates a symmetry axis running along $0^{\circ}$ $180^{\circ}$ direction $[60,61]$. At the side of the ridge $\left(0^{\circ}\right)$, stresses are the most compressive, and yet complicated. Opposite to that side $\left(180^{\circ}\right)$, compressive stresses are extremely small in magnitude. Due to this profound weakness, premature cracking is often expected at the side of ridge (split) during loading. Therefore, it is often recommended to align the split along the major loading axis of the component to avoid the risk of any inopportune failure from this side sometimes during, and particularly after the cold expansion process. Hence, reliable compressive stress distributions can be located on either sides of the hole, which are $90^{\circ}$ off from the position of the split. Thus, residual stresses

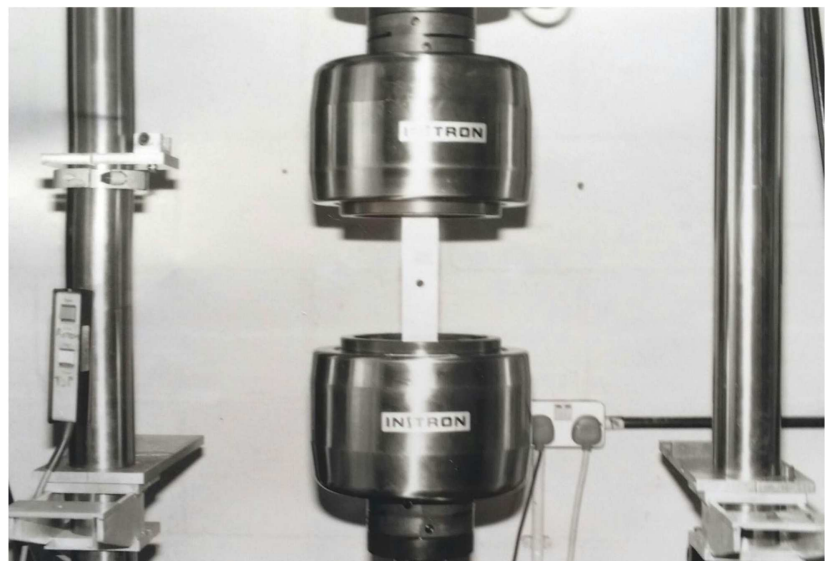

Figure 2. Plate specimen under fatigue cycling fixed with hydraulic grips.

located at $90^{\circ}$ and $270^{\circ}$ positions can be observed to be similar. As a result, typical main load-experienced sides are usually preferred to be at $90^{\circ}$ and $270^{\circ}$ positions, respectively. In practical aircraft applications, sudden gust storms (biaxial loading) during flight may be dangerous and cold expansion residual stresses may relax fully to nil, and sudden detrimental cracks may occur at $0^{\circ}$ side of the hole. In other words, the main external loading direction is almost preferred to be kept parallel to the axis of cold expansion symmetry to get the maximum benefit out of the holed part and its reliability in service.

Fatigue test was carried out at constant amplitude loading in laboratory air using an 'Instron' servohydraulic testing machine with a $100 \mathrm{kN}$ load cell at a frequency of $10 \mathrm{~Hz}$ (Figure 2). To hold specimens, hydraulic grips were used to reinforce the gripping, and to avoid premature failure, small square steel plates were bonded to each end of the specimen.

As can be seen from the experimental S-N curves presented in the previous work [8], fatigue limit of the specimens at $R=0.1$ was found to be the maximum stress of $150 \mathrm{MPa}$. At this loading condition, specimens could withstand up to 6.5 million cycles without breaking. In this work, the degree of stress variation at the beginning of fatigue was considered. In doing so, specimens cycled at the fatigue limit for 50,100 , and 125 thousand cycles were used to work on the three-dimensional redistribution of the residual hoop stress at $90^{\circ}$ position of the hole, which is the side perpendicular to the load axis.

Replication technique was used to monitor crack initiation and growth from the inner surface of the hole and on the plate surface. Specimens were cycled at the fatigue limit of $150 \mathrm{MPa}$ and replicas from cracks were taken. Cracking was also monitored from the specimens used for residual stress experiments.

\subsection{Residual stress measurements}

$40 \mathrm{~mm}$ discs with central cold expanded and reamed 
holes were extracted from the original plates to measure residual stresses. This was achieved by electric discharge machining. Although this delicate processing did not introduce additive residual stresses, the removal of the washer changed the true stress distribution $[10,28,30]$. Thus, $1 \mathrm{~mm}$ strain gauge in the hoop direction was affixed to the bore of the hole at $90^{\circ}$ position before cutting out the disc. Typical recorded strains are less than 200 micro-strains. By using a compensation equation derived from Lamé equations for turning down [30], the lost original residual stress value, particularly at the bore at most was found to be at most $12 \mathrm{MPa}$. Compared to the magnitude of residual stresses, error was small. Mostly, this value was ignored in some other studies, yet was compensated in the calculations of residual stresses in the present work. Thus, the hoop stress relaxed during washer production and so the compensation equation is given as follows:

$$
\Delta \sigma_{\theta}(r)=\frac{\Delta \varepsilon_{\theta} E}{2}\left(\frac{a^{2}+r^{2}}{r^{2}}\right),
$$

where $E$ is the modulus of elasticity, $\Delta \varepsilon_{\theta}$ is the change in the hoop strain at the edge of the hole when original washer is cut from the rectangular plate, $r$ is any arbitrary washer size, and $a$ symbolizes the radius of the hole.

The washers were then successively fixed to a specimen holder. To complete the Wheatstone-Bridge circuit, a dummy specimen was connected to compensate for temperature effect during spark erosion cutting process. In principle, the methodology of Sachs hole drilling was adopted, where the technique involves enlarging the hole incrementally (Figure 3) [28-30].

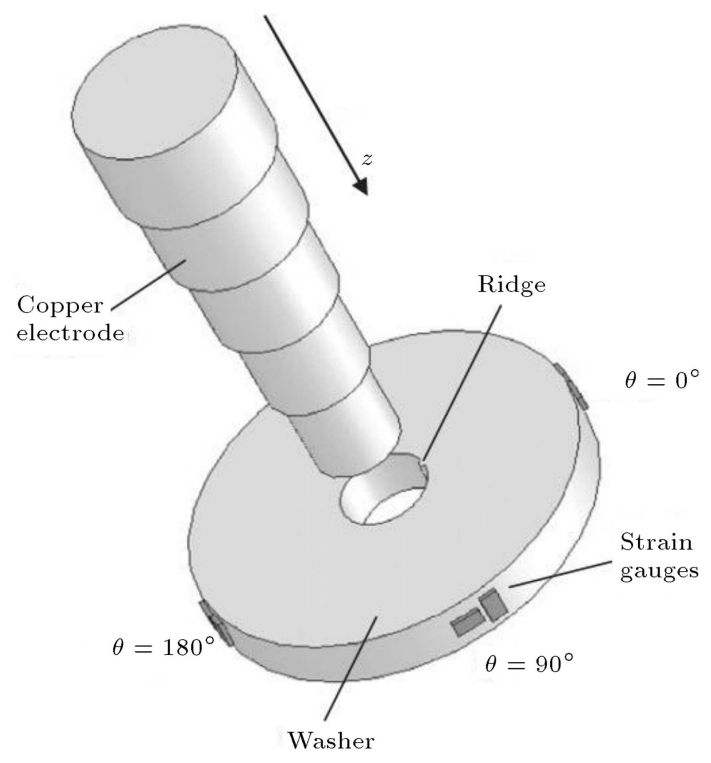

Figure 3. Copper electrode and washer with strain gauges used during step-drilling process.
To determine residual stresses, measuring incremental changes in strains (from the washer periphery) with increasing hole radius was essentially required [51-53]. Therefore, strain gauge pairs (hoop and transverse in directions) were attached to the perimeter.

\subsection{Two-dimensional analysis}

Sachs (hole-drilling) method is simple and limited to measure the average of the stress distribution through the thickness direction of tubes and discs [24,51-53]. For two-dimensional stress analyses, direct through cuts of small concentric layers from the bore are required. The technique is based on the force balance between the discarded layer and the remaining portion of the disc. Residual stresses at any arbitrary control radius, $r$, in the cross-section change gradually as the washer has been bored out close to $r$. Layer $d r$ at $r$ holds some stresses until that layer is also removed. The complete stress tensor at the vicinity of the hole can be evaluated from hoop, $\varepsilon_{\theta}$, and longitudinal, $\varepsilon_{z}$, strains measured from the circumference of the disc. Hence, the generalized Sachs equation is given as follows:

$$
\sigma_{\theta}(r)=E^{\prime}\left[\left(\frac{b^{2}-r^{2}}{2 r}\right) \frac{d \Theta^{0}}{d r}-\left(\frac{b^{2}+r^{2}}{2 r^{2}}\right) \Theta^{0}\right] .
$$

Experimental principles of Sachs and Fourier methods are the same. Moreover, the mathematics of Sachs method is simple and practically easy to use; the method is restricted to quantify the axisymmetric residual stresses [28-30]. Hence, Fourier series analysis was introduced to verify the non-axisymmetric nature of the residual stresses at cold expanded holes [3234]. The method involves Fourier series expansion of measured strain functions and residual stresses as in terms of radial distance, $r$, from the hole and angular variation, $\theta$, around the hole. To represent hoop stresses in polar coordinates, the general equation is as follows:

$$
\sigma_{\theta}(r, \theta)=\sum_{m=0}^{\infty}\left(\sigma_{\theta}^{m A}(r) \cos m \theta+\sigma_{\theta}^{m B}(r) \sin m \theta\right),
$$

where $\sigma_{\theta}^{m A}$ and $\sigma_{\theta}^{m B}$ are the coefficients and have to be sufficient in number to achieve an accurate measure of the non-axisymmetry of the residual hoop stress distribution. FTI cold expanded holes have asymmetric axes and pass across the hole in the pip to the opposite side of the pip direction. By taking this into account, the Fourier series simplifies and reduces to:

$$
\sigma_{\theta}(r, \theta)=\sum_{m=0}^{\infty}\left(\sigma_{\theta}^{m A} \cos m \theta\right) .
$$

Fourier series method has been revised lately [40,41]. The technique is simply the superposition of both axisymmetric and non-axisymmetric expressions derived for stress distribution. Herein, $\sigma_{\theta}^{0}$ represents the 
standard Sachs solution, and other higher orders, $\sigma_{\theta}^{1 A}$ and $\sigma_{\theta}^{2 A}$, correspond to non-symmetric solving part of the residual hoop stress. Hence, residual hoop stress distribution at any orientation around a cold expanded hole can be expressed by the subsequent equation as follows:

$$
\begin{aligned}
\sigma_{\theta}(r, \theta)= & E^{\prime}\left[\left(\frac{b^{2}-r^{2}}{2 r}\right) \frac{d \Theta^{0}}{d r}+\left(\frac{b^{4}-r^{4}}{4 b r^{2}}\right) \frac{d \Theta^{1 A}}{d r} \cos \theta\right. \\
& +\left[\frac{\left(b^{2}-r^{2}\right)^{2}}{4 r\left(b^{2}+r^{2}\right)}\right] \frac{d \Theta^{2 A}}{d r} \cos 2 \theta-\left(\frac{b^{2}+r^{2}}{2 r^{2}}\right) \Theta^{0} \\
& -\left(\frac{b 4+r^{4}}{2 b r^{3}}\right) \Theta^{1 A} \cos \theta \\
& +\left(\frac{r^{6}-b^{7}-b^{2} r+9 b^{2} r^{4}-4 b^{4} r^{2}}{4 r^{2} b^{4}+4 r^{6}+8 r^{4} b^{2}}\right) \\
& \left.\Theta^{2 A} \cos 2 \theta\right] .
\end{aligned}
$$

For both Sachs and Fourier series solution methods (i.e., Eqs. (2) and (5)), $b$ symbolizes the outer radius of the washer, $r$ is the any arbitrary radius of the hole, and $\theta$ is the angular variation as measured from the pip. $E^{\prime}=E /\left(1-\mu^{2}\right)$ and $\Theta^{0}=\varepsilon_{\theta}+\mu \varepsilon_{z}$, where $E$ and $\mu$ are moduli of elasticity and Poisson's ratio, and $\varepsilon_{\theta}$ and $\varepsilon_{z}$ are the hoop and longitudinal strains that can experimentally be measured from the perimeter. Eq. (2) is valid for the two-dimensional representation of the average of the through-thickness residual hoop stress, $\sigma_{\theta}(r)$ changes in the radial direction, $r$, at a certain orientation of the hole when the stress field is axisymmetric. Nevertheless, in the case of asymmetric stress pattern around the hole, Eq. (5) is functional to determine the non-axisymmetric character of residual hoop stress, $\sigma_{\theta}(r, \theta)$, in two dimensions. Herein, in the equation, $\Theta^{0}$ terms represent the standard Sachs solution, where $\Theta^{1 A}$ and $\Theta^{2 A}$ terms correspond to the non-symmetric solutions. Thus, the mean throughthickness residual hoop stress, $\sigma_{\theta}(r, \theta)$, varying both in radial distance $r$ and at any angular variation $\theta$ around the hole can be evaluated.

\subsection{Three-dimensional analysis by step drilling method}

In the present work, Fourier series solution was preferred to verify the through-thickness stress distributions. Simply, the methodology of hole step-drilling was adopted and practiced using spark erosion via a copper electrode. By means of step-wise material removal around the bore as small circular slices of equal steps (i.e. $0.5 \mathrm{~mm}$ ) through the thickness, threedimensional strain data were measured by the use of a pair of strain gauge attached to the mid-section of the

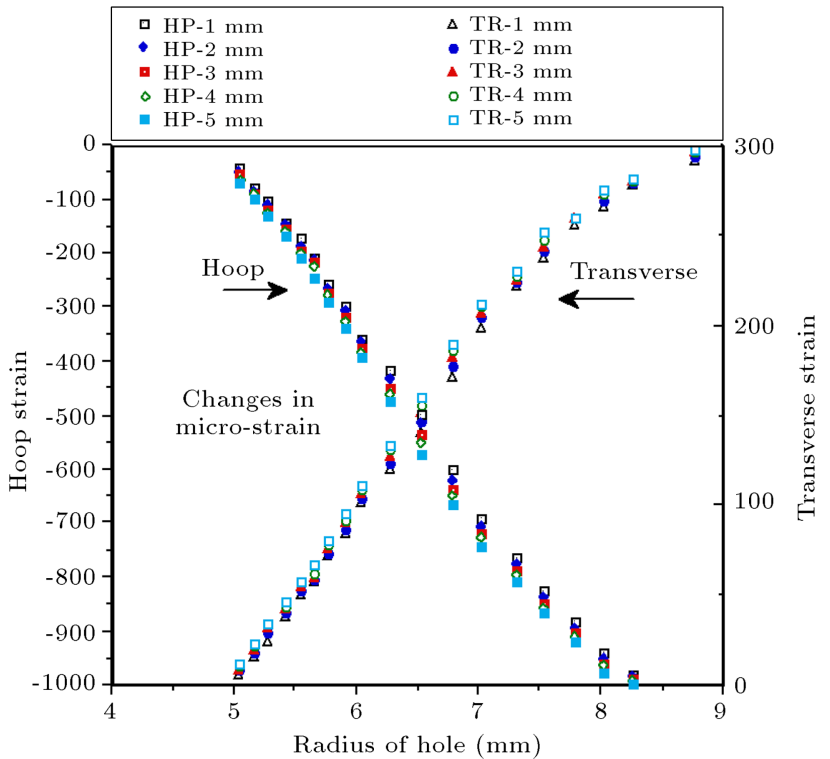

Figure 4. Typical plot of hoop (HP) and transverse (TR) micro-strain measurements recorded during step-drilling procedure of a $4 \%$ FTI cold expanded hole.

perimeter of the disc at $90^{\circ}$ position. At each step, hole drilling was interrupted to record the strains from the gauges. Attention was paid to attain stable readings that varied at most $\pm 3 \mu \varepsilon$. In this way, at any diameter of the hole, the rate of change in strains with respect to the depth of drilling was recorded (Figure 4). With these data, three-dimensional residual stress fields were constructed.

It was claimed that using precise criteria creates great intractability that can only be overcome by making simplified assumptions $[12,24]$. Considering that residual stresses are self-equilibrating, it was assumed that, after the relief of the stress in the discharged segment, the remaining parts redistribute the residual stress uniformly to reestablish the balance. Thus, the plane-sections-remain-plane assumption holds after each step of drill.

In this work, during drilling the steps through the thickness, the longitudinal strains being observed were negligibly small in magnitude (less than $1 \mu \varepsilon$ ); so, axial bending of the washer was ignored during drilling.

For the ordinary Sachs method, the Lame' and equilibrium equations for elastic case in thick-walled cylinders together with the general elastic stress-strain relationship are considered and the following expression is written:

$$
\sigma_{\theta}^{0}\left(\frac{d z}{z_{0}}\right)=\frac{d}{d r}\left[E^{\prime} \Theta^{0}\left(\frac{b^{2}-r^{2}}{2 r}\right)\right] .
$$

For detailed stress analysis, mathematical expressions for the technique of step-drilling and Fourier series solution have been overlaid. As mentioned before, this method is called the combined step-drilling and Fourier 
series solution (ATÖzdemir method) $[40,41,60,61]$. The validity of this method was previously approved by neutron diffraction $[29,31,39,40,41]$ and synchrotron methods [45] and, recently, by Artificial Neural Networks (ANN) solutions $[60,61]$.

For complete three-dimensional residual hoop stress distribution at any orientation around the hole, the general equation can be given as follows:

$$
\begin{aligned}
\sigma_{\theta}(r, z, \theta)= & E^{\prime} z_{o}\left[\left(\frac{b^{2}-r^{2}}{2 r}\right) \frac{\partial \Theta^{0}}{\partial r \partial z}\right. \\
& +\left(\frac{b^{4}-r^{4}}{4 b r^{2}}\right) \frac{\partial \Theta^{1 A}}{\partial r \partial z} \cos \theta \\
& +\left[\frac{\left(b^{2}-r^{2}\right)^{2}}{4 r\left(b^{2}+r^{2}\right)}\right] \frac{\partial \Theta^{2 A}}{\partial r \partial z} \cos 2 \theta \\
& -\left(\frac{b^{2}+r^{2}}{2 r^{2}}\right) \frac{\partial \Theta^{0}}{\partial z} \\
& -\left(\frac{b 4+r^{4}}{2 b r^{3}}\right) \frac{\partial \Theta^{1 A}}{\partial z} \cos \theta \\
& +\left(\frac{r^{6}-b^{6}-b^{2} r+9 b^{2} r^{4}-4 b^{4} r^{2}}{4 r^{2} b^{4}+4 r^{6}+8 r^{4} b^{2}}\right) \\
& \left.\frac{\partial \Theta^{2 A}}{\partial z} \cos 2 \theta\right],
\end{aligned}
$$

where $z_{o}$ is the thickness of the washer. Both Eqs. (5) and (7) involve the series expansions of measured incremental strain function, $\Theta^{0}$ stands for the standard Sachs solution, and the remaining $\Theta^{1 A}$ and $\Theta^{2 A}$ correspond to the non-symmetric solutions to the residual stress distribution problem. In addition, considering the changes in radial distance, $r$, and angular variation, $\theta$, around the hole, Eq. (6) can verify the changes in stress incrementally along the thickness of the bore.

In the present work, the strain data has been collected only from the fatigue loaded side of the hole. Thus, Eq. (7) has been solved for $\theta=90^{\circ}$, where residual hoop stress distribution at $90^{\circ}$ position of a cold expanded hole can be expressed by the following equation as:

$$
\begin{gathered}
\sigma_{\theta}\left(r, z, 90^{\circ}\right)=E^{\prime} z_{o}\left[\left(\frac{b^{2}-c^{2}}{2 c}\right) \frac{\partial \Theta^{0}}{\partial c \partial z}\right. \\
-\left[\frac{\left(b^{2}-c^{2}\right)}{4 c\left(b^{2}+c^{2}\right)}\right] \frac{\partial \Theta^{2 A}}{\partial c \partial z}-\left(\frac{b^{2}+c^{2}}{2 c^{2}}\right) \frac{\partial \Theta^{0}}{\partial z} \\
\left.-\left(\frac{c^{6}-b^{6}-b^{2} c+9 b^{2} c^{4}-4 b^{4} c^{2}}{4 c^{2} b^{4}+4 c^{6}+8 c^{4} b^{2}}\right) \frac{\partial \Theta^{2 A}}{\partial z}\right] .
\end{gathered}
$$

As it is clear that the second and fourth terms in Eq. (8) are negligibly small, the remaining first and third terms with $\Theta^{0}$ are governing the mathematical solutions to determine the residual stresses at this orientation. Thus, Eq. (8) simply reduces to:

$$
\begin{aligned}
\sigma_{\theta}\left(r, z, 90^{\circ}\right)= & E^{\prime} z_{o}\left[\left(\frac{b^{2}-c^{2}}{2 c}\right) \frac{\partial \Theta^{0}}{\partial c \partial z}\right. \\
& \left.-\left(\frac{b^{2}+c^{2}}{2 c^{2}}\right) \frac{\partial \Theta^{0}}{\partial z}\right] .
\end{aligned}
$$

Thus, Fourier solution approaches to that of Sachs, and the above equation stands for the Sachs modified step cutting technique $[40,41]$. The advantage is that residual stresses perpendicular to the load axis can easily be measured by putting a single strain gauge couple on the perimeter of the disc at $90^{\circ}$ position. Normally, the results of Sachs and Fourier solutions are different $[40,41]$. However, only at $90^{\circ}$ (or $270^{\circ}$ ) position of the hole, residual hoop stress distributions predicted by both methods are in good agreement and very similar in the magnitude as well as the distribution (Figures 5 and 6).

It is evident that during stress analyses, single curve fit routine strain versus hole radius can result in uneven estimates of residual stress distributions [10]. However, precise knowledge of the residual stress field is required. To represent all the features, the data were divided into small discrete parts, and a separate polynomial was fitted to each of these divisions. For the most favorable distribution, stress values obtained from each portion were eventually splined by fitting an overall-high order polynomial [40,41]. Thus, to illustrate all detailed features, strain functions, $\Theta^{0}$, $\Theta^{1 A}$, and $\Theta^{2 A}$, corresponding to $90^{\circ}$ position were cal-

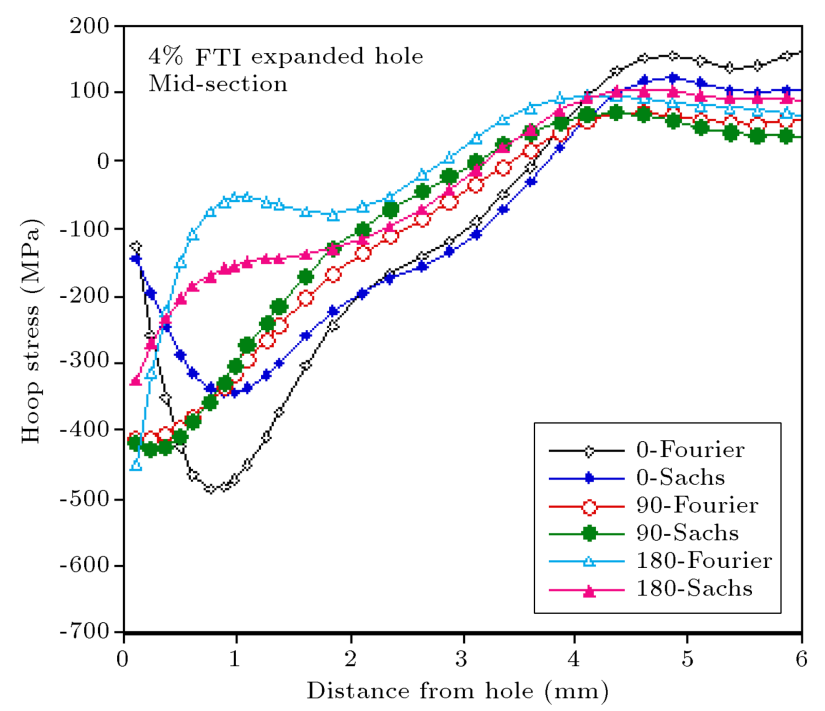

Figure 5. Two-dimensional residual hoop stress distributions measured by Fourier series and Sachs methods for certain orientations around $4 \%$ FTI cold expanded (unreamed) hole. 


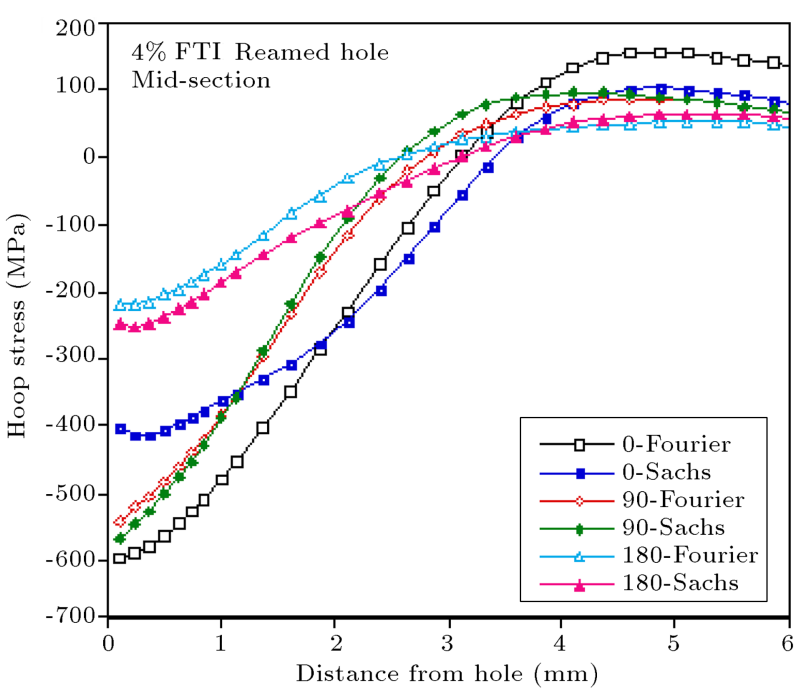

Figure 6. Two-dimensional residual hoop stress distributions measured by Fourier series and Sachs methods for certain orientations around 4\% FTI cold expanded and reamed hole.

culated. In doing so, a multiple-curve fitting program was used where the positions and inflections in the strain data were employed to reproduce these inflections accurately whilst illustrating the two-dimensional and three-dimensional natures of the residual stress distributions.

\section{Results and discussion}

Linear Elastic Fracture Mechanics-based (LEFM) damage tolerance estimation has been successfully used for many years and is in fact a part of the regular regime of many safety critical sectors such as the aircraft industry. However, there are still some troubles in applying the principles of damage tolerance to components containing considerable residual stress fields. With recently developed advances in residual stress measuring techniques, new evidence on the interaction between fatigue cracks and residual stress fields has been achieved.

Recent attempts to measure residual stresses accurately have confirmed the complexity of stresses after cold expansion [28-30,37-39,45]. How these stresses can withstand external loads is still a question. The majority of research so far suggests that fatigue life modelling and predictions for critical airframes containing cold expanded holes rely on precise determination of initial and current distributions of the residual stresses during cyclic loading $[3,8,39,43,66,68-72,74]$. The stability of the initial distribution is of prime importance. However, high stress levels can alter the stress field, where residual stress redistributes and reaches a new self-equilibrating state. Generally, high remote stress levels (gust loads) degrade the fatigue endurance by relaxing the useful intensity of the compressive stress, thus reducing the beneficial effect of cold expansion. It is apparent that the change in residual stress pattern affects S-N life, and particularly, fatigue crack growth period can be altered. Thus, the details of crack growth are not well represented with initial growth usually being underestimated and further growth being overestimated. It is now known that this is mostly due to residual stress rearrangements. Hence, incorrect assumptions about residual stress distribution and life predictions may be a serious fault, endangering the aircraft safety.

\subsection{Distribution of residual stresses}

Residual stresses around FTI cold expanded holes are not axisymmetric. By nature, FTI expanded holes have a typical symmetric axis running along $0^{\circ}-180^{\circ}$ direction. Thus, the full residual stress distributions surrounding the holes are in fact symmetric about this symmetric axis. This is due to the complex plastic history of the cold expansion, where the most compressive residual stresses are located at the vicinity of the split $\left(0^{\circ}\right)$. The least compressive stresses in contrast are positioned at the opposite side. It is clear that results of the stress measurements via Sachs and Fourier methods are normally different, but only are in a good conformity at $90^{\circ}$ position residual stress distributions (Figures 5 and 6 ). For the same material (7050 T76), identical hole, and specimen's geometry, good agreements are also found between the stresses measured by ATÖzdemir method (ATÖ) and some other diffraction techniques (i.e., Neutron $[29,31,39,40,41]$ and Synchrotron [45]) predicted by ANN [60,61] (Figure 7). Figure 7 presents all residual

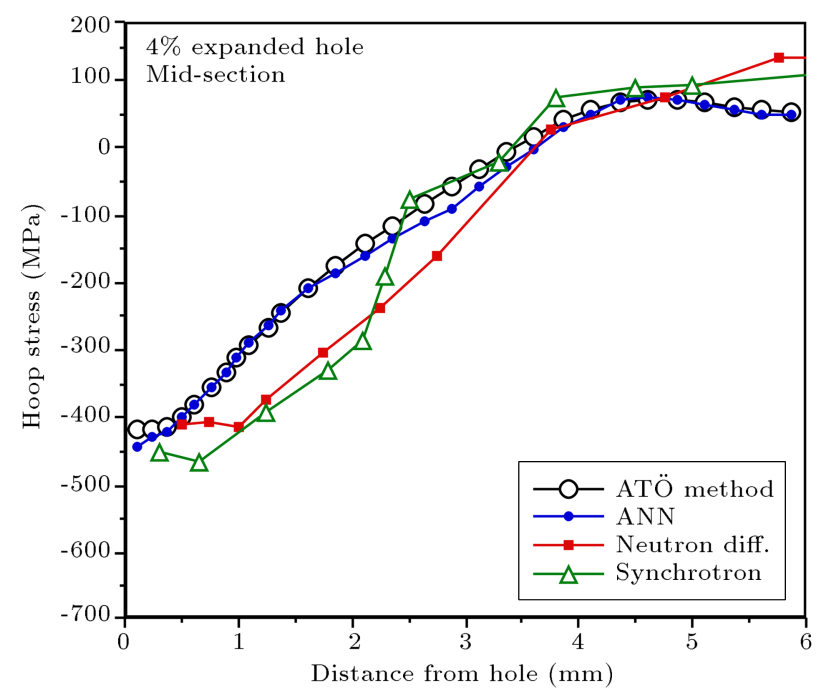

Figure 7. Comparison of residual hoop stress distributions at mid-section of $4 \%$ FTI expanded hole at $90^{\circ}$ (or $270^{\circ}$ ) position determined by ATÖ $[40,41,61]$, neutron diffraction [29,31,40,41], and synchrotron [45] techniques and predicted by ANN modelling [60,61], respectively. 


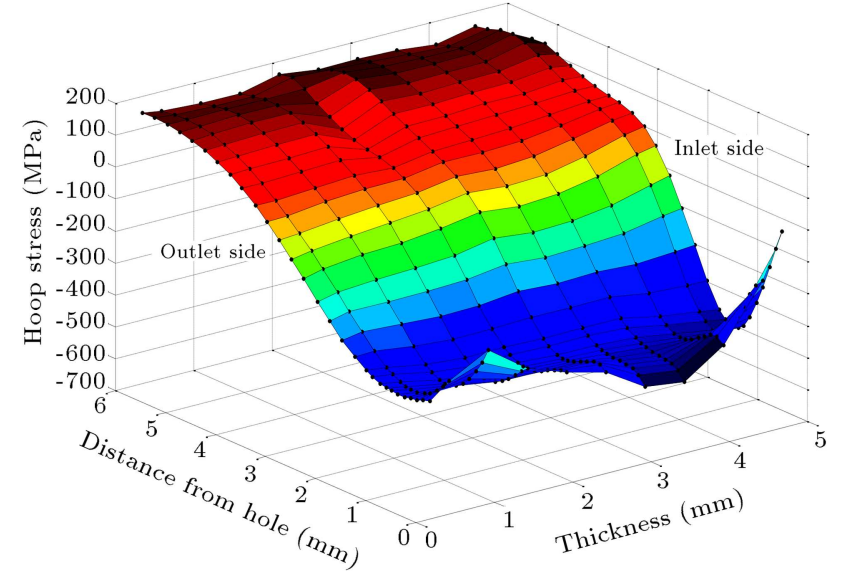

Figure 8. Three-dimensional residual hoop stress topography determined by ATÖ method for $4 \%$ FTI cold expanded hole at $90^{\circ}$ ( or $270^{\circ}$ ) position before reaming.

stress distributions that are valid for the mid-section at $90^{\circ}$ (or $270^{\circ}$ ) position match in reasonable precision.

Three-dimensional residual stress distributions are complex. There are remarkable disparities between maximum and minimum values and distributions of residual stresses through the thickness of the plate. To illustrate, hoop stress topography at $90^{\circ}$ (or $270^{\circ}$ ) position for a split-sleeve cold expanded hole (before fatigue cycling) is sketched in Figure 8. As clear from the figure, considerable reverse yielding occurs on each plate surface, where the amount of reverse yielding at the inlet side is substantial with respect to that of the outlet side. In contrast, reverse yielding at the mid-section is negligible, such that the maximum compressive hoop stress lies on the edge of the hole $(-395 \mathrm{MPa})$. This is due to the complex nature of the expansion process. Due to extensive material constraint, the plain-strain condition dominates at the mid-section and plane-stress condition is effective in each plate surface $[40,74]$. Thus, split-sleeve cold expanded holes are weak at inlet sides where cracking often starts at high service loads.

\subsection{Effect of finishing processes}

Machining techniques, such as cutting and turning, naturally induce residual stresses on the part of the surface as a byproduct of the thermal cycling, microstructural transformations, and deformation associated with material separation [62]. These machininginduced residual stresses, typically of much smaller magnitude with shallow depth, are also subject to potential relaxation and redistribution.

Reaming is a standard machining process after cold expansion to bring the hole to correct fitting of precision before joining. In the present work, reaming the hole, where some material has been removed from the bore, is about $0.3 \mathrm{~mm}$. Corners of the hole have also been de-burred $(0.2 \mathrm{~mm})$ to reduce the sharpness. It is

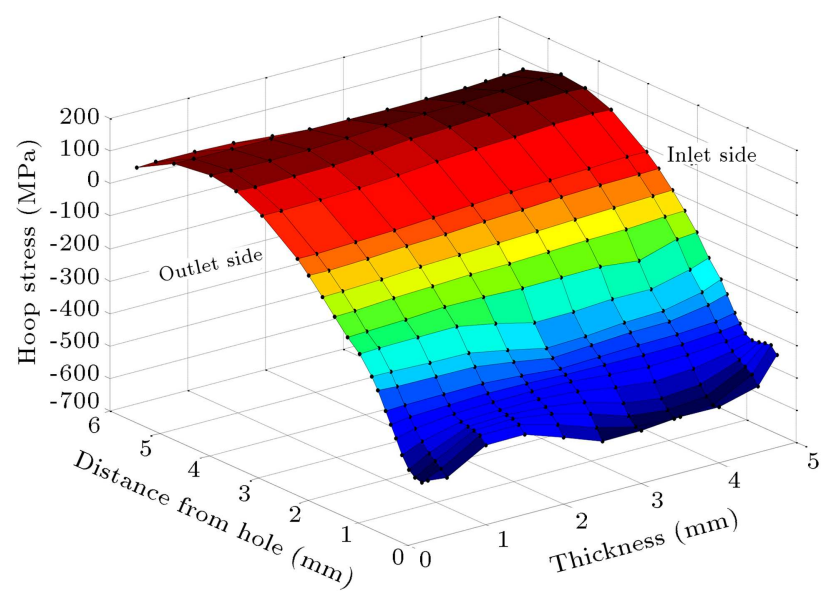

Figure 9. Three-dimensional residual hoop stress topography determined by ATÖ method for $4 \%$ FTI cold expanded and finish-reamed hole at $90^{\circ}$ (or $270^{\circ}$ ) position, before fatigue cycling.

evident that these finishing processes have increased and redistributed the compressive residual stresses, where the maximum compressive stress has been moved to lie at the surface of the bore (Figures 8 and 9) $[8,40]$. As illustrated in Figure 9, stress distribution along the bore is smoothened. However, the maximum compressive stress at the inlet side $(-490 \mathrm{MPa})$ is still less than that of the outlet side $(-530 \mathrm{MPa})$ and the mid-section $(-510 \mathrm{MPa})$, respectively. An explanation can be made when constraints of the sections are considered. After cold expansion, the forces initially restrained at the mid-section are larger than the forces retained at the plate surface. However, after reaming, particularly during de-burring, plane-stress condition on the surface is disturbed and quasi-plane-strain conditions are left behind. This is because of the strong cutting shear forces involved from the corner towards inside along the bore. Cutting forces in fact are transformed to radial, hoop, and axial components by rotation of the tool and transferred to the near hole material $[62,63]$. These forces diminish progressively even at mid-section, still affecting the constraint; the plane-strain condition is progressively more dictating, where the resulting forces maintained at different segments along the bore come about similar in magnitude. Consequently, material removal from around and corners of the hole has remarkable effect on the final distribution of residual stresses along the bore.

\subsection{Redistribution of residual stress fields during fatigue}

The beneficial effect of compressive residual stresses on fatigue performance has been practiced successfully in many fields of engineering. Even though the assumed mechanism of life improvement has been taken to be the suppression of fatigue crack initiation for many years, at present, it is evident that effects on fatigue 
crack growth rate can at least be as important as the crack initiation.

To illustrate this, the fatigue crack propagation behavior from a hole in a similar 7050-T76 plate was examined both with and without the presence of a residual stress field due to cold expansion [8]. It was clear that cold expansion of the hole has high beneficial effects on fatigue life, where both process times of initiation and crack growth were retarded by the compression of the residual stresses adjacent to the hole. For the plain hole, failure occurred very rapidly after the initiation of a crack that is about $4 \times 10^{4}$ cycles. In contrast, the cold expanded hole exhibited considerable improvement in fatigue life. Although main cracks were initiated $\left(10^{5}\right.$ cycles $)$ at both sides of the hole, they were finally arrested after about $10^{6}$ cycles with different rates of growth, where the test sample did not fail at the applied stress level of $150 \mathrm{MPa}$. This means that even cracks were initiated due to the stress concentration at the hole and slowly grew through a compressive residual stress field; finally, they were arrested effectively, making them safe as long as the compression of the residual stresses does not further loosen up because of plasticity. Thus, $150 \mathrm{MPa}$ corresponds to the stress limit below which the samples do not fail during fatigue process and, so, could withstand over $10^{7}$ cycles without failure.

In the present work, aluminum plate specimens with central holes cold expanded by $4 \%$ were fatigue tested under the same conditions (maximum stress of $150 \mathrm{MPa}$ ) for 50, 100, and 125 thousand cycles to investigate the effect of early fatigue on the redistribution of residual stresses at $90^{\circ}$ (or $270^{\circ}$ ) position. Thus, the variations in full residual hoop stress fields after 50, 100, and 125 thousand cycles are shown in Figures 10-12, respectively. In addition, successive redistributions of residual stresses at certain sections through the thickness are presented in Figures 13-15. Certainly, hoop stresses close to the bore are selfrearranging incessantly. At the beginning of fatigue (50 thousand cycles), compressive stresses next to the bore are increasing (Figure 10). Residual stresses at both outlet and inlet hole sides are about $-500 \mathrm{MPa}$ (Figures 13 and 15). On the other hand, at mid-section, residual stress at the edge of the hole is almost -540 $\mathrm{MPa}$ (Figure 14). However, maximum compressive stresses are all positioned at about $0.4 \mathrm{~mm}$ from the hole, where they are $-550 \mathrm{MPa},-570 \mathrm{MPa}$, and $-590 \mathrm{MPa}$ for outlet, inlet, and mid-section regions, respectively.

At 100 thousand cycles, the maximum compressive stress on the inlet plate surface rapidly decreases and stress distribution at this region reverts to the original stress distribution just before fatigue testing (Figures 11 and 15). At the end of 125 thousand cycles, a fast relaxation goes on at this site, where stress at the

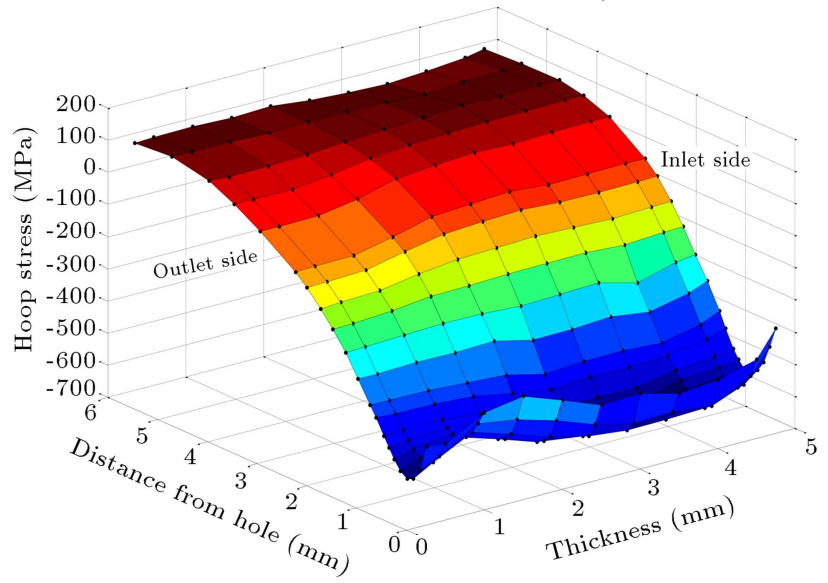

Figure 10. Three-dimensional residual hoop stress topography determined by ATÖ method for $4 \%$ FTI cold expanded and finish-reamed hole at $90^{\circ}$ ( or $270^{\circ}$ ) position after $50 \times 10^{3}$ cycles.

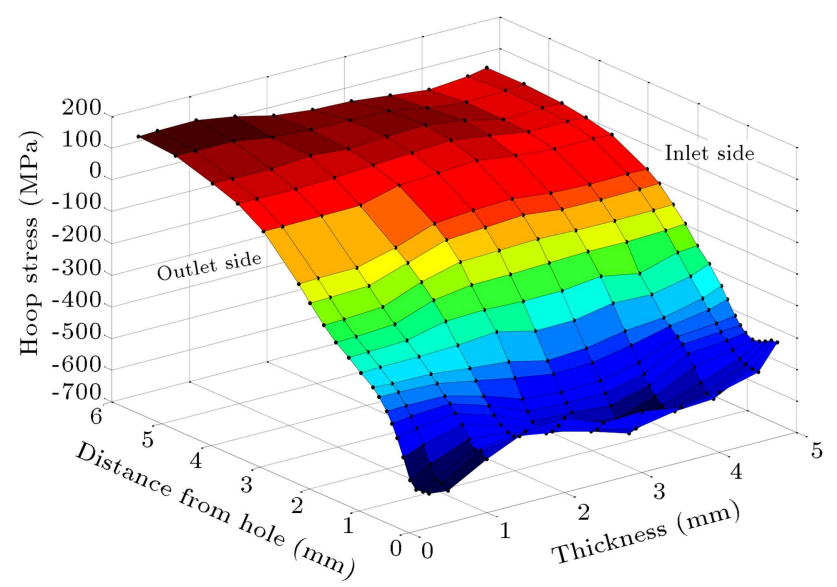

Figure 11. Three-dimensional residual hoop stress topography determined by ATÖ method for $4 \%$ FTI cold expanded and finish-reamed hole at $90^{\circ}$ ( or $270^{\circ}$ ) position after $100 \times 10^{3}$ cycles.

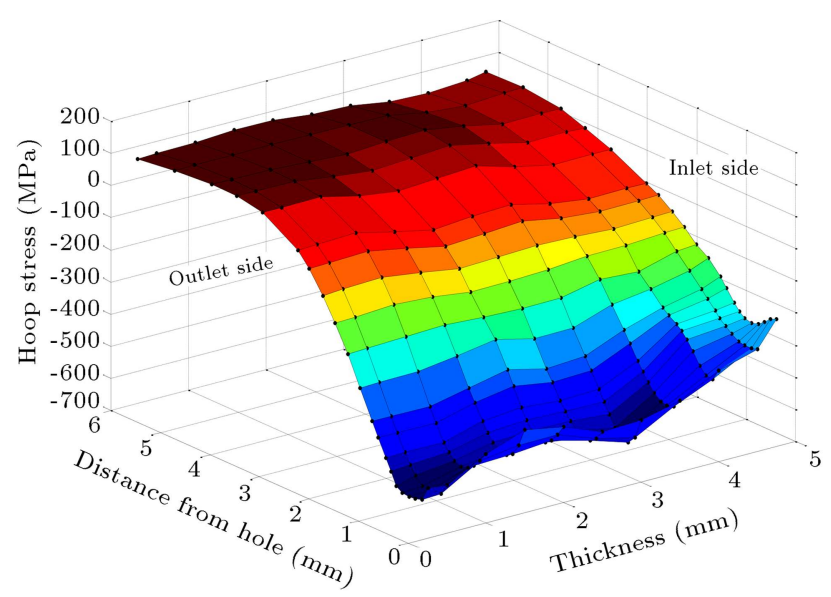

Figure 12. Three-dimensional residual hoop stress topography determined by ATÖ method for $4 \%$ FTI cold expanded and finish-reamed hole at $90^{\circ}$ ( or $270^{\circ}$ ) position after $125 \times 10^{3}$ cycles. 


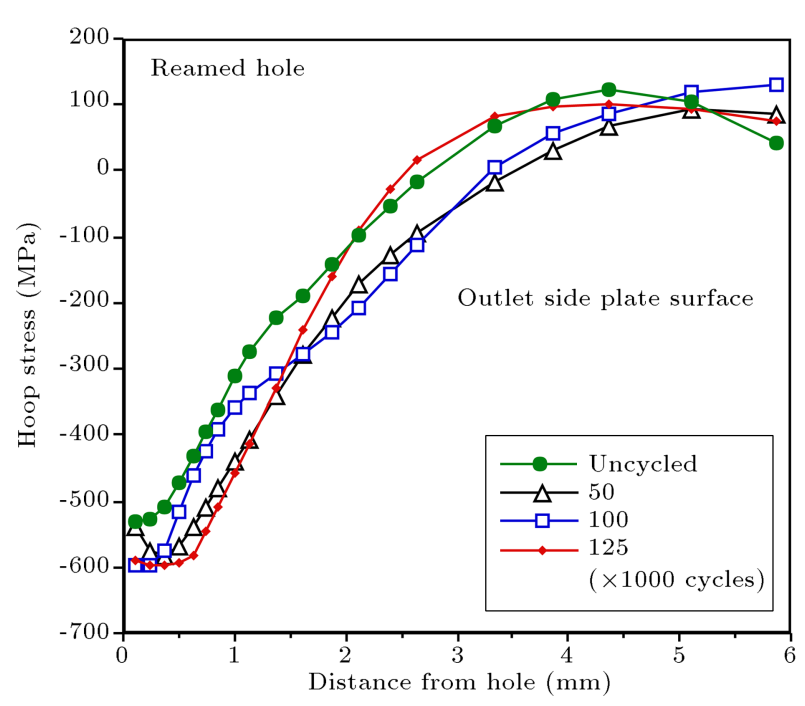

Figure 13. Changes in residual hoop stress distribution on outlet plate surface of $4 \%$ FTI cold expanded and finish-reamed hole at $90^{\circ}$ (or $270^{\circ}$ ) position during early fatigue cycling.

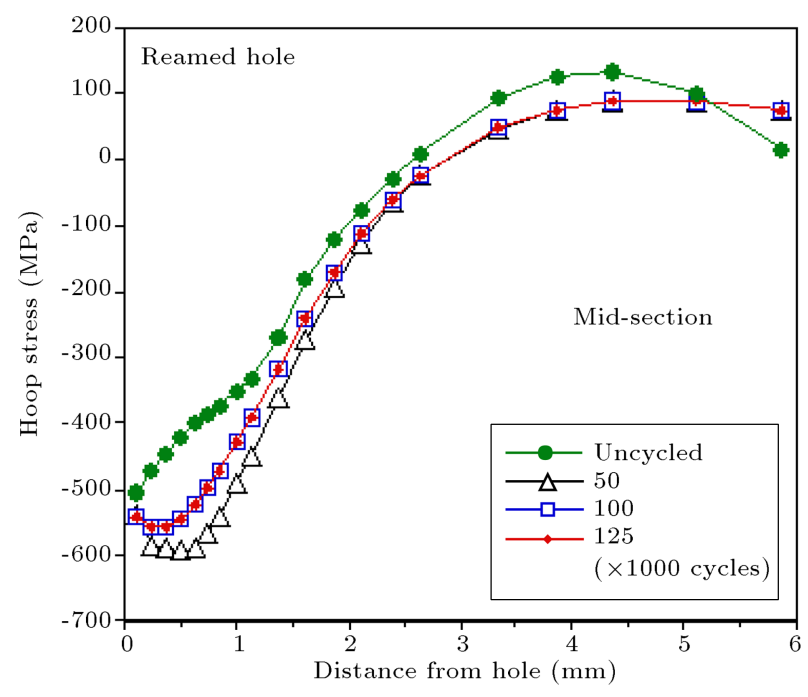

Figure 14. Changes in residual hoop stress distribution at mid-section of $4 \%$ FTI cold expanded and finish-reamed hole at $90^{\circ}$ (or $270^{\circ}$ ) position during early fatigue cycling.

bore is about $-300 \mathrm{MPa}$, and the maximum compressive stress $0.4 \mathrm{~mm}$ from the hole is around $-340 \mathrm{MPa}$ (Figures 12 and 15). In contrast, stress values close to the outlet side are continuously increasing (Figures 1013). At 100 thousand cycles, the maximum stress at the outlet corner is about $-585 \mathrm{MPa}$; after 125 cycles, it reaches the tensile strength of the material, which is about $-600 \mathrm{MPa}$ (Figure 13). Thus, stress distribution next to the hole fluctuates and the position of the maximum stress moves towards the bore. However, at mid-section, after 100 thousand cycles, the maximum compressive stress progressively reduces to $-560 \mathrm{MPa}$, where further fatiguing up to 125 thousand cycles and stress distribution at mid-section remains stationary

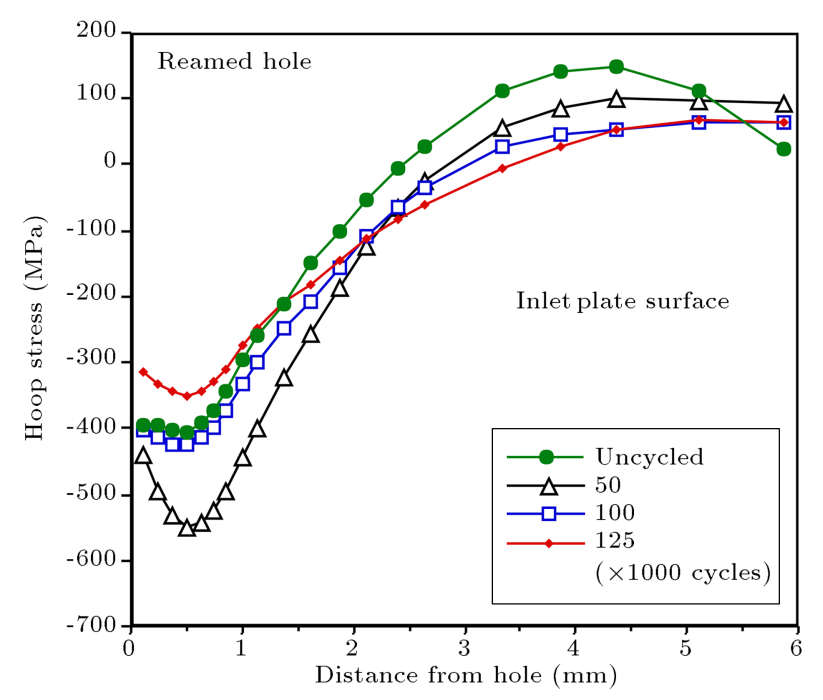

Figure 15. Changes in residual hoop stress distribution on inlet plate surface of $4 \%$ FTI cold expanded and finish-reamed hole at $90^{\circ}$ (or $270^{\circ}$ ) position during early fatigue cycling.

(Figure 14). Thus, mid-section stress distribution is between the distributions of inlet and outlet stresses to satisfy the compatibility along the bore of the hole.

So far, extensive literature has covered so many results of several reports, particularly on the relaxation of residual stresses at cold expanded holes, where the decay in stress has been always attributed to micro-plasticity or sometimes cracking about the hole $[8,66,72,74]$. From the point of micro-plasticity, cyclic hardening and softening in precipitation-hardened aluminum alloys is mostly promoted by a mechanism in which the precipitate geometry and distribution as well as dislocation-particle interactions can be altered by cyclic straining. Existing experimental evidence reveals that initial cyclic hardening occurs in these materials due to an increase in dislocation density and dislocation-precipitate interactions $[75,76]$. Contrarily, cyclic softening is highly favored if the precipitates in the age-hardened alloy are easily sheared by dislocations, i.e. if they are fine, closely spaced, and coherent with the matrix. A particularly interesting feature of deformation in these alloys is that the formation of Persistent Slip Bands (PSBs) causes cyclic softening without reaching a saturation stage. There are several mechanisms proposed for rationalized cyclic softening in these materials [76]. So far, the current research has shown that, after cold expansion of aluminum alloys, cyclic softening is generally promoting [42]. On the other hand, prior static cold working by extrusion or rolling introduces a high and reasonably uniform slip band density. In $\mathrm{Al}$ and $\mathrm{Cu}$ alloys, a stronger delineation of sub-boundaries during fatigue following the cold working is preeminent. However, when compression and tension tests on the fatigued specimens to eliminate possible effects of fatigue cracks 
upon static properties were carried out, it was noticed that cyclically softening (recovery mechanisms) of cold worked metals could only occur above the fatigue limit [77]. However, above and below the fatigue limit, a high slip band density can always be developed by cyclic stress, where, in fact, there is no significant difference in the density of the slip bands when metals are stressed in the safe or unsafe ranges.

It should be noted that the material used in this work is a precipitation hardened high strength 7050 aluminum alloy; in all previous works related with this material, cyclic softening was preeminent before cracking. As stated before, in this study, a transitory cyclic hardening has been observed during the first 100 thousand cycles of fatiguing when tests have been conducted at the fatigue limit of the samples. Therefore, as one might expect, at the fatigue limit of a cold expanded hole, decay of stress is not favored. Thus, at the beginning of cycling, without sub-boundary formation, PSBs develop and possibly the cracks within them, too. Occasionally, small cracks can develop early in the fatigue test, but they remain stagnant thereafter. Moreover, incipient cracks can only start after several thousand cycles.

The general trend exhibited so far by the results is that applied load can provide a large change in the residual stress field, almost certainly due to micro-plastic deformation or crack initiation at a cold expanded hole. In the present work, therefore, due to the lack of softening micro-recovery mechanisms, dislocation density and compressive stresses at the surface increase in magnitude before cracking starts. Relaxation in residual hoop stress at the inlet side is in fact a good coincidence with the detection of a shallow crack initiating from inside the bore at the inlet [8]. At 50 thousand cycles, a very small crack $(0.05 \mathrm{~mm})$ has first come into view from the inlet side. It has progressed along the bore through the thickness reaching 0.1 and $0.8 \mathrm{~mm}$ in length after 100 and 125 thousand cycles, respectively. Only after 125 thousand cycles, a very tiny short crack of about $0.05 \mathrm{~mm}$ size on the inlet plate surface could be spotted. Thus, a semi-elliptical crack has formed at the inlet side of the hole [8]. On the contrary, during this period, nothing has happened at the outlet side. Cracking and decay in residual stresses could not be noticed. Only a second short crack $(0.175 \mathrm{~mm})$ starting from the outlet corner towards the inner surface of the hole could be marked later after 230 thousand cycles without any sign of cracking on the plate surface [8]. Consequently, relaxation in stress at the inlet side can simply be accredited to the premature cracking taking place from the plate corner. A similar apparent effect of cracking on systematic changes in residual stress distributions was also reported elsewhere [42].

It is apparent that even after reaming and de- burring, fatigue cracking still starts from the mandrel entrance side of the hole, particularly from the corner, and a short crack propagates on the surface of the bore. This is related to the complex three-dimensional distortion of the material at the bore on mandrel-in and mandrel-out faces of the $[29,40]$. The purpose of using sleeve in the expansion process is to homogenize the plastic deformation about the hole [3]; there are still dissimilarities in the material constraint along the length of the bore. While the constraint is maximized at mid-section (plain-strain), the sliding mandrel minimizes the material constraint at the vicinity of the inlet corner [74]. The state of stress at the inlet side is, therefore, the plane-stress condition. On the contrary, outlet side experiences a mixed-mode state of stress, as being partially plane-stress is more likely deviating towards plain-strain condition. This difference in plasticity can easily be observed from the distance of the elasticplastic boundary from the hole, which is the position of the maximum tensile stress after cold expansion. In Figure 9, after reaming and de-burring, the plastic zone size for inlet site is about $4 \mathrm{~mm}$, where for both middle and outlet sites are around $4.5 \mathrm{~mm}$. During fatigue cycling, the sizes of plastic zones are continually alternating (Figures 10-12). However, on average, the distance of the elastic-plastic boundary measured from the bore is still small for the inlet side (Figures 13-15). During cold expansion, due to considerable sideways expansion on the inlet plate surface, the degree of radial expansion of the hole is somewhat insufficient. Owing to this, the least compressive residual stresses are generated at this side of the hole. However, this is not the only reason why cracks primarily initiate from the inlet side of the hole (Figure 16). At the beginning of fatigue cycling, residual stresses along the

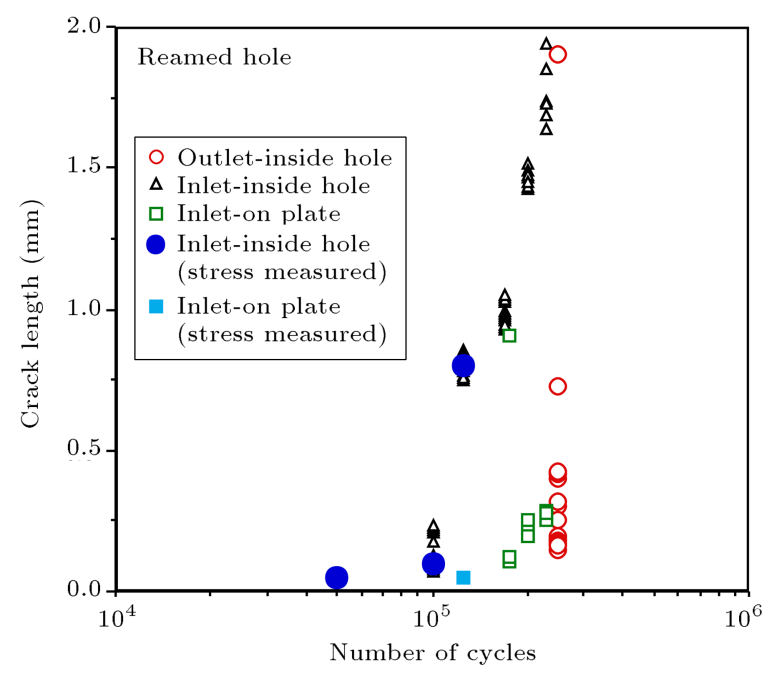

Figure 16. Crack growth measurements taken from outlet and inlet sides of $90^{\circ}$ and $270^{\circ}$ position of several $4 \%$ FTI cold expanded and finished-reamed holes at the fatigue limit of $150 \mathrm{MPa}$. 
bore systematically become more compressive (Figures 13-15). After reaching critical high compressive values, cracking nevertheless starts from the inlet side causing a simultaneous relaxation in residual hoop stresses within this area (Figure 15). On the other hand, stresses particularly at the outlet side can reach higher compressive values before cracking (Figure 13). This may be again due to the mixed-mode stress state condition acting at this site. Micro-plasticity seems to have an effect on the variation of residual stress distribution along the bore, and the onset of stress decay almost coincides with a detectable short fatigue crack initiation after some numbers of fatigue cycles. Thus, a substantially faster crack initiation rate and a greater crack growth distance are promoted in planestress rather than in plane-strain [78]. The plane-strain condition causes a large crack closure load than planestress. Therefore, the crack remains open during a larger fraction of the compression cycle in plane-stress rather than in plane-strain.

Researches so far have confirmed that the traditional FTI split-sleeve cold expansion technique unavoidably introduces asymmetric three-dimensional compressive residual stresses along the planar and through thickness directions around the hole [60,61]. As the residual compressive stresses induced on the entry side of the mandrel passage are somewhat less and so weak than those at the mid-section, and at the existing side of the mandrel, a new crack can typically initiate at the opposite outlet side of the hole only after an initial fatigue crack at the inlet side has grown to a number of millimeters [79]. These findings facilitate the fact that either at or below the fatigue limit, a cold expanded sample does not fail during fatigue, but crack initiation may still occur slowly. Extensive decay in residual stress, therefore, occurs only because of the passage of the fatigue crack. Hence, during fatigue loading at the fatigue limit, crack initiation and growth is the main cause of the relaxation of the residual stress field at a cold expanded hole.

\section{Conclusions}

FTI cold expansion is a complex process introducing irregularities in stress distribution from the mandrel entrance towards the exiting side of the hole. As a trend, the generated residual stresses close to the bore are considerably low at the side mandrel slides. After finish-reaming and de-burring processes, stress distribution along the bore becomes more compressive and unvarying. However, the residual hoop stresses at or near the mandrel entrance side are still less compressive than those in the remaining section. Threedimensional nature of the variation of residual stresses at $4 \%$ cold expanded and finish-reamed holes during early fatigue has been constructed on the basis of
ATÖzdemir method (the novel step drilling-Fourier series solution), where the available two- and threedimensional experimental data have been systematically used. Results reveal that residual stress fields in the through-thickness direction are continuously changing during fatigue. At the fatigue limit, cyclic softening cannot occur due to the lack of plastic recovery mechanisms. Accordingly, at the early stage of cycling, compressive stresses next to the bore tend to increase temporarily. After reaching a critical level, massive relaxation in residual hoop stresses starts from the inlet side, where small fatigue cracks initiate and grow at the corner and later on the plate surface. This is believed to be due to the plane-stress conditions effectively acting on inlet side of the expanded hole.

\section{References}

1. Mann, J.L. and Jost, G.S. "Stress fields associated with fitted and cold expanded holes", Metal Forum, 6, pp. 43-53 (1983).

2. Schwarmann, L. "On improving fatigue performance of a double shear lap joint", Int. J. Fatigue, 2, pp. 105-111 (1982).

3. Champoux, R.L. "An overview of cold expansion methods", In Fatigue Prevention and Design, pp. 3552, J.T. Barnby, Ed., Camelot Press, London, UK (1986).

4. Lowak, H. "Fatigue life increase by mechanically induced compressive residual stresses; the influence of component size, load history and load level" [Zum einfluss von bauteilgrösse, lastfolge und last horizon auf die schwingfestigskeit-steigerung durch mechanisch erzeugte eigenspannungen], Bericht Nr. FB-157, Fraunhofer-Institut Für Betriebsfestigkeit, Darmstadt (1981).

5. Jongebreur, A.A. and Koning, U.A. "Results of a study of residual stresses and fatigue crack growth in lugs with expanded holes", Int. Conf. on Aircraft Fatigue, ICAF' 83, 2, R. Labourette and D. Deviller, Eds., CEAT, France, pp. 39-51 (1983).

6. Ozelton, M.W. and Coyle, T.G. "Fatigue life improvement by cold working fastener holes in 7050 aluminium", Fatigue in Mechanically Fastener Composites and Metallic Joints, ASTM STP 927 John M Potter, Ed., pp. 53-71 (1986).

7. Pell, R.A., Weawer, P.W., Mann, J.Y., and Sparrow, J.G. "Fatigue of thick-section cold expanded holes with and without cracks", Fat. and Frac. Engng. Mater. Struct, 12, pp. 553-567 (1989).

8. Özdemir, A.T. and Edwards, L. "Relaxation of residual stresses at cold expanded holes due to fatigue loading", Fat. and Frac. Engng. Mater. Struct., 20, pp. 1443-1451 (1997).

9. Özdemir, A.T. and Edwards, L. "Residual stresses at expanded holes in 7010 plate", Technical Report No. 
FRG/94/1/10, Report of Work Specified in Alcan Int. Ltd. Purchase Order 66217, UK (1994).

10. Özdemir, A.T. and Hermann, R. "Effect of expansion technique and plate thickness on near hole residual stresses and fatigue life of cold expanded holes", $J$. Mater. Sci, 34, pp. 1243-1252 (1999).

11. Ramsberg, W. and Osgood, W.R. "Description of stress-strain curves by three parameters", Technical Report No. NACA TN 902, National Advisory Committee for Aeronautics, Washington DC, USA (1943).

12. Hill, R. "The expansion of a cylindrical tube", The Mathematical Theory of Plasticity, pp. 100-124, Oxford University Press, Oxford, UK (1950).

13. Nadai, A. "Partial yielding in cylinders", The Theory of Flow and Fracture in Solids, pp. 458-471, McGrawHill Book Co., New York (1950).

14. Hsu, Y.C. and Foreman, R.G. "Elastic plastic analysis of an infinite sheet having a circular hole under pressure", ASME, J. Appl. Mech., 42, pp. 347-352 (1975).

15. Zhang, Y., Fitzpatrick, M.E., and Edwards, L. "Analysis of the residual stress around a cold-expanded fastener hole in a finite plate", Strain, 41, pp. 59-70 (2005).

16. Rich, D.L. and Impellizzeri, L.F. "Fatigue analysis of cold worked and interference fit fastener holes", Cyclic Stress-Strain and Plastic Deformation Aspects of Fatigue Crack Growth, ASTM STP 637, pp. 153-177 (1977).

17. Chen, P.C.T. "A new method of predicting residual stress in autofrettaged gun barrels", Technical Report No. ARCCB-TR-86012, US Army Armament Research and Development Center, Watervliet, USA (1986).

18. Wu-Xue, Z. and Zi-Chu, Z. "An elastic-plastic analysis of autofrettaged thick-walled cylinders", Acta Mech. Sinica, 19, pp. 245-255 (1987).

19. Wang, G.S. "An elastic-plastic solution for a normally loaded centre hole in a finite circular body", Int. J. Press. Vess. Piping, 33, pp. 269-284 (1988).

20. Megahed, M.M. and Abbas, A.T. "Influence of reverse yielding on residual stress by autofrettage", Int. J. Mech. Sci., 33, pp. 139-150 (1991).

21. Poussard, G.C., Pavier, M.J., and Smith, D.J. "Analytical and finite element predictions of residual stresses in cold worked fastener holes", J. Strain Analy., 30, pp. 291-304 (1995).

22. Ball, D.L. "Elastic-plastic stress analysis of cold expanded fastener holes", Fat. and Frac. Engng. Mater. Struct., 18, pp. 47-63 (1995).

23. Carey, R.P. "Computed stress and strain distributions under interference fit and after cold working", Technical Report No. AR-904-548, Aeronautical Research Laboratories, Melbourne, Victoria, Australia (1987).

24. Denton, A.A. "Determination of residual stresses", Metall. Rew., 11, pp. 101-123 (1966).
25. Dietrich, G. and Potter, J.M. "Stress measurements on cold worked fastener holes", Adv. in X-Ray Anal., 20, pp. 321-328 (1977).

26. Stacey, A., MacGillivary, H.J., Webster, G.A., Webster, P.J., and Ziebeck, K.R.A. "Measurement of residual by neutron diffraction", J. Strain Analy., 20(2), pp. 93-100 (1985).

27. Cook, R. and Holdway, P. "Residual stresses induced by hole expansion", Conf. on Computer Methods and Experimental Measurements for Surface Treatment Effects, M.H. Aliabadi and C.A. Brebbia, Eds., Computational Mechanics Publications, Southampton, UK, pp. 91-100 (1993).

28. Özdemir, A.T., Cook, R., and Edwards, L. "Residual stress distributions around cold expanded holes", Conf. on Durability and Structural Integrity of Airframes, ICAF '93, International Committee on Aircraft Fatigue, A.F. Blom, Ed., 1, (EMAS, Cradley Heath, West Midlands, pp. 207-23 (1993).

29. Özdemir, A.T., Wang, D.Q. and Edwards, L. "Measurement of the $3 \mathrm{D}$ residual stress distribution at split sleeve cold expanded holes", 4th Int. Conf. on Residual Stresses, ICRS-4, Society for Experimental Mechanics Publications, Bethel, USA, pp. 1144-1149 (1994).

30. Özdemir, A.T. and Edwards, L. "Measurement of the three-dimensional residual stress distribution around split sleeve cold expanded holes", J. Strain Analy., 31, pp. 413-421 (1996).

31. Edwards, L. and Wang, D.Q. "Neutron diffraction determination of the complete $3 \mathrm{D}$ residual stress distribution surrounding a cold expanded hole", 4th European Conf. on Residual Stresses, S. Denis, Ed., Société Francaise de Métallurgie et de Matériaux, 2, Bourgogne, France, pp. 619-626 (1998).

32. Garcia-Granada, A.A., Lacarac, V., Smith, D.J., Pavier, M.J., Cook, R., and Holdway, P. "3D residual stresses around cold expanded holes in a new creep resistant aluminium alloy", Conf. on Surface Treatment $I V$, VIT Press, pp. 103-116 (1999).

33. Garcia-Granada, A.A., Smith, D.J., and Pavier, M.J. "A new procedure based on sachs' boring for measuring non-axisymmetric residual stresses", Int. J. Mech. Sci., 42, pp. 1027-1047 (2000).

34. Lacarac, V., Garcia-Granada, A.A., Smith, D.J., and Pavier, M.J. "The effect of creep on residual stress relaxation around cold expanded holes", 6th Int. Conf. on Residual Stresses, ICRS 6, Institute of Materials, 1, Oxford, UK, pp. 117-121 (2000).

35. Pyzalla, A. "Stress and strain measurements: X-rays and neutrons", Physica B: Condensed Matter, 276278, pp. 833-836 (2000).

36. Webster, P.J., Mills, G., Browne, P.A., Hughes, D.J., and Holden, T.M. "Residual stress around a cold expanded hole", 6th Int. Conf. on Residual Stresses, ICRS-4, Institute of Materials, 1, Oxford, UK, pp. 125131 (2000). 
37. Stefanescu, D., Edwards, L., and Fitzpatrick, M.E. "XRay diffraction measurement of the residual stresses surrounding a cold expanded hole", Mater. Sci. Forum, 404(4), pp. 185-190 (2002).

38. Stefanescu, D. "Experimental study of double cold expansion of holes", J. Strain Analysis, 38(4), pp. 339347 (2003).

39. Stefanescu, D., Dutta, M., Wang, D.Q., Edwards, L., and Fitzpatrick, M.E. "The effect of high compressive loading on residual stresses and fatigue crack growth at cold expanded holes", J. Strain Analysis, 38(5), pp. 419-427 (2003).

40. Özdemir, A.T. and Edwards, L. "Through-thickness residual stress distribution after the cold expansion of fastener holes and its effect on fracturing", ASME $J$. Eng. Mat and Tech., 126, pp.129-135 (2004).

41. Özdemir A.T. and Edwards, L. "An assessment of the complete through thickness residual stress distribution after the split sleeve cold expansion of fastener holes", Can. Met. Quarterly, 43(2), pp. 239-248 (2004).

42. Stefanescu, D. "Measurement and prediction of fatigue crack growth from cold expanded holes. Part 1: The effect of fatigue crack growth on cold expansion residual stresses", J. Strain Analysis, 39(1), pp. 25-40 (2004).

43. Stefanescu, D. "Measurement and prediction of fatigue crack growth from cold expanded holes. Part 2: Prediction of fatigue crack growth from cold expanded holes", J. Strain Analysis, 39(1), pp. 41-54 (2004).

44. Stefanescu, D., Santisteban, J.R., Edwards, L., and Fitzpatrick, M.E. "Residual stress measurements and fatigue crack growth prediction of cracked fastener holes", J. Aerospace Eng., 7, pp. 91-97 (2004).

45. Stefanescu, D., Steuwer, A., Owen, R.A., Nadri, B., Edwards, L., Fitzpatrick, M.E., and Withers, P.J. "Elastic strains around cracked cold-expanded fastener holes measured using the synchrotron x-ray diffraction technique", J. Strain Analysis, 39(5), pp. 459-469 (2004).

46. Matos, P.F.P., Moreira, P.M.G.P., Nedbal, I., and de Castro, P.M.S.T. "Reconstitution of fatigue crack growth in Al-Alloy 2024-T3 open-hole specimens using microfractographic techniques", Eng. Fract. Mech., 72, pp. 2232-2246 (2005).

47. Pina, J.C.P., Dias, A.M., de Matos, P.F.P., Moreira, P.M.G.P., and Castro, P.M.S.T. "Residual stress analysis near a cold expanded hole in a textured alclad sheet using x-ray diffraction", Experimental Mech., 45(1), pp. 83-88 (2005).

48. Matos, P.F.P., McEvily, A.J., Moreira, P.M.G.P., and de Castro, P.M.S.T. "Analysis of the effect of coldworking of rivet holes on the fatigue life of an aluminum alloy", Int. J. of Fatigue, 29, pp. 575-586 (2007).

49. Sinha, S.K. "The impact of synchrotron radiation on nanoscience", Appl. Surf. Sci., 182, pp. 176-185 (2001).
50. Withers, P.J. "Use of synchrotron x-ray radiation for stress measurement", Analysis of Residual Stress by Diffraction Using Neutron and Synchrotron Radiation, M.E. Fitzpatrick and A. Lodini, Eds., Taylor and Francis, London, UK (2002).

51. Sachs, G. "Demonstration of residual stresses in rods and tubes" [Der nachweis innerer spannungen in stangen und rohren], Z. Metall., 19, pp.352-362 (1927).

52. Lambert, J.W. "A method of deriving residual stress equations", Proc. Soc. Exp. Stress Analy., 12, pp. 9198 (1954).

53. Weiss, V. "Residual stresses in cylinders", Proc. Soc. Exp. Stress Analy., 15, pp. 53-61 (1960).

54. Kamal, S.M. Borsaikia, C., and Dixit, U.S. "Experimental assessment of residual stresses induced by the thermal autofrettage of thick-walled cylinders", $J$. Strain Analy., 12, pp. 1-17 (2015).

55. Poussard, G.C., Pavier, M.J., and Smith, D.J. "A finite element simulation of the cold working process for fastener holes", J. Strain Analy., 32(4), pp. 287-300 (1997).

56. Forgues, S.A., Bernard, M., and Bui-Quioc, T. "3D axisymmetric numerical analysis and experimental study of the fastener hole cold working", Conf. on Computer Methods and Experimental Measurements for Surface Treatment Effects, M.H. Aliabadi and C.A. Brebbia, Eds., Computational Mechanics Publications, Southampton, UK, pp. 61-70 (1993).

57. Pavier, M.J., Poussard, G.C., and Smith, D.J. "Effect of residual stress around cold worked holes on fracture under superimposed mechanical load", Engng. Frac. Mech., 63, pp. 751-773 (1999).

58. Lacarac, V., Smith, D.J., Pavier, M.J., and Priest, M. "Fatigue crack growth from plain and cold expanded holes in aluminium alloys ", Int. J. Fatigue, 22, pp. 189-203 (2000).

59. Kang, J., Johnson, W.S., and Clark, D.A. "Threedimensional finite element analysis of the cold expansion of fastener holes in two aluminium alloys", ASME J. Engng. Mater. Tech., 124(2), pp. 140-145 (2002).

60. Özdemir, A.T. and Toktaş "Contemporary analyses in assessing residual stress topographic images enclosing a cold expanded hole", Can. Met. Quarterly, 47(1), pp. $59-70$ (2008).

61. Toktaş, İ. and Özdemir, A.T. "Artificial neural networks solution to display residual hoop stress field encircling a split-sleeve cold expanded aircraft fastener hole", Expert Systems with Applications, 38, pp. 553563 (2011).

62. McClung, R.C. "A literature survey on the stability and significance of residual stresses during fatigue", Fatigue and Fract. Engng Mater. Struct., 30, pp. 173205 (2006).

63. Maximov, J.T., Duncheva, G.V., and Amudjev, I.M. "A novel method and tool which enhance the fatigue life of structural components with fastener holes", Engng. Failure Analysis, 31, pp. 132-143 (2013). 
64. Maximov, J.T., Duncheva, G.V., Ganev, N., and Amudjev, I.M. "Modeling of residual stress distribution around fastener holes in thin plates after symmetric cold expansion", J. Braz. Soc. Mech. Sci. Engng., 36, pp. 355-369 (2014).

65. Yucan, Fu., Ende, Ge., Honghua, Su., Jiuhua, Xu., and Renzheng, Li. "Cold expansion technology of connection holes in aircraft structures: A review and prospect", Chinese J. Aeronautics, 28(4), pp. 961-973 (2015).

66. Chakherlou, T.N., Tabrizi, Y.A., and Kiani, A. "On the fatigue behavior of cold expanded fastener holes subjected to bolt tightening", Int. J. Fatigue, 33, pp. 800-810 (2011).

67. Taghizadeh, H., Chakherlou, T.N., Ghorbani, A., and Mohammadpour, A. "Prediction of fatigue life in cold expanded fastener holes subjected to bolt tightening in Al alloy 7075-T6 plate", Int. J. Mechanical Sciences, 90, pp. 6-15 (2015).

68. Wallace, P.W. and Frankel, P.J. "Relief of residual stresses by single fatigue cycle", Weld. J., 38, pp. 565574 (1949).

69. Morrow, J. and Sinclair, G.M. "Cyclic dependent stress relaxation", In Symposium on Basic Mechanisms Fatigue, ASTM STP 237, ASTM International, 100 Barr Harbor Drive, PO Box C700, West Conshohocken, PA19428-2959, USA (1958).

70. Kodama, S. "The behaviour of residual stress during fatigue stress cycles", 2nd Int. Conf. on Mechanical Behaviour of Metals, Society of Material Science, Kyoto, Japan, 2, pp. 111-118 (1972).

71. Jhansale, H.R. and Topper, T.H. "Engineering analysis of the inelastic stress response of a structural metal under variable cyclic strains", In Cyclic Stress Strain Behaviour Analysis, Experimentation and Failure Prediction, ASME, West Conshohocken, PA, USA, pp. 246-270 (1973).

72. Zhuang, W.Z. and Halford, G.R. "Investigation of residual stress relaxation under cyclic loading", Int. J. Fatigue, 23, pp. 31-37 (2001).
73. Jones, K.W. and Dunn, M.L. "Predicting corner fatigue propagation from cold expanded holes", Engng. Fract. Mechs., 76, pp. 2074-2090 (2009).

74. Chakherlou, T.N. and Yaghobi, A. "Numerical simulation of residual stress relaxation around a coldexpanded hole under longitudinal cyclic loading using different kinematic hardening models", Fat. Fract. Engng. Mater. Struct., 33, pp. 740-751 (2010).

75. Brett, S. and Doherty, R.D. "Loss of solute at the fracture surface in fatigued aluminium precipitation hardened alloy", Mater. Sci. Engng., 32(3), pp. 255265 (1978).

76. Edgar, A., Starke, Jr., and Lütjering, G. "Cyclic plastic deformation and microstructure", Fatigue and Microstructure, ASM, pp. 205-243 (1978).

77. Polakowski, N.H. and Palchoudhuri, A. "Softening of certain metals under the action of fatigue loads", Proc. American Society for Testing Materials, ASTM, ASTEA, 54, pp. 701-716 (1954).

78. Holm, D.K., Blom, A.F., and Suresh, S. "Growth of cracks cyclic under far field compressive loads: Numerical and experimental results", Engng. Fract. Mechs., 23, pp. 1097-1106 (1986).

79. Stefanescu, D., Edwards, L., and Fitzpatrick, M.E. "Fatigue cracks at holes", Int. J. Fatigue, 25(7), pp. $569-576$ (2003).

\section{Biography}

Abbas Tamer Özdemir received BSc and MSc degrees from Middle East Technical University (METU). He received his $\mathrm{PhD}$ from the Open University, UK. Since 1995, he has been working as a lecturer in Gazi University. He is a Professor in the field of Materials Engineering, mostly interested in thermodynamics, physical, and mechanical metallurgy. He is currently working on residual stresses, composite materials, and cryogenics. 